\title{
Application of 4D BIM modelling in planning and construction of zero cycle works
}

\author{
Vladimir Konyushkov ${ }^{1, *}$, Sergey Sotnikov ${ }^{1}$, Vladislav Veretennikov ${ }^{1}$, and Ivan Ershov ${ }^{1}$ \\ ${ }^{1}$ Saint Petersburg State University of Architecture and Civil Engineering, Saint Petersburg, Russia
}

\begin{abstract}
D BIM modeling is a unique and effective management technology in construction projects. However, it is not widely used in geotechnical construction. This paper summarizes main aspects that characterize the essence of this new technology. An extensive literature review and analysis of 'pilot' projects were conducted. The main 4D modeling tools are presented. As a result of the study of ongoing projects, a calculation of the economic efficiency by implementation of this technology was made. The use of this method in planning and construction can increase the main criteria for assessing the success and effectiveness of zero-cycle work.
\end{abstract}

\section{Introduction}

Most modern geotechnical tasks require the use of modern information modeling. In geotechnics, as in other areas of construction, one cannot do without the use of these technologies. In the vast majority of cases, designers and project managers are confronted with a large number of factors that impede the development of structural parts of buildings and the construction of bases and foundations: uncertainty in choosing the best technological solution, building in conditions of tight construction, the complex geometry of buildings and structures, the problem of communication between participants and others. All of these factors can be taken into account by introducing new management approaches into the field of geotechnics construction based on the use of building information models (BIM).

\section{Materials and methods}

The zero cycle of the construction of any structures takes a significant part of the time from the duration of the entire project. The work performed during this period precedes the works on the construction of aboveground structures and cannot be carried out parallel to them. Standard construction methods do not provide an opportunity to see all the construction processes that are interconnected. The visibility of 4D BIM allows you to identify all possible organizational technological solutions that can significantly reduce the time and optimize the consumption of resources [1] during the construction of a structure. One example that clearly demonstrates the decision made on the basis of the 4D model to

\footnotetext{
* Corresponding author: v.konyushkov@yandex.ru
} 
conduct parallel work on the grips for the construction of an artificial land plot and for the construction of the front wall of the sea pier is shown in figure 1.

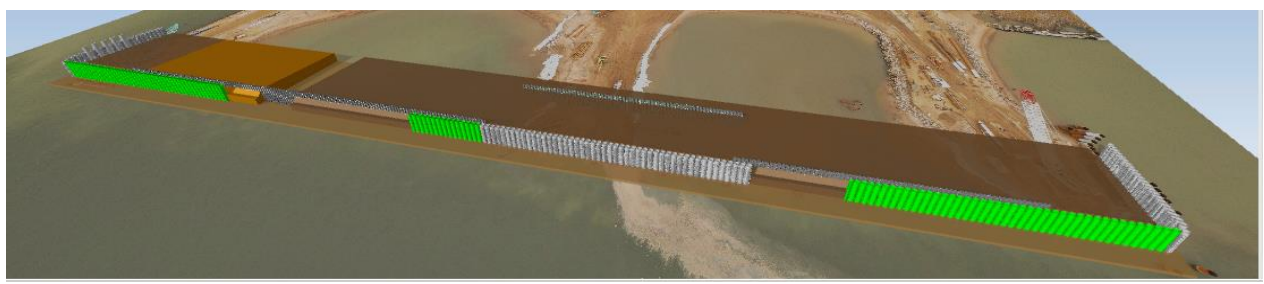

Fig. 1. 4D BIM model of a sea pier.

BIM (Building Information Modeling) is a new principle in construction, which is just beginning to be actively developed and implemented in design institutes, engineering companies, customer structures, affects and rethinks the relationship of the parties in all existing areas. It is worth noting that the concept of BIM is not limited to the narrow specifics of application in design, which is usually implied, but also allows all participants from related areas to participate in the implementation of projects. This principle can significantly improve geotechnical construction. The main goal of implementing information technology in geotechnical construction is to increase the efficiency of designing, planning and conducting zero-cycle work.

To date, the generally accepted structure of BIM dividing is the Beau-Richards "maturity level" model [2], presented in figure 2, which demonstrates the transition from classical drawing CAD systems (level 0 ) to some ideal iBIM solution that works in a single environment, combining a multidisciplinary model, project management, financial analysis and control (level 3).

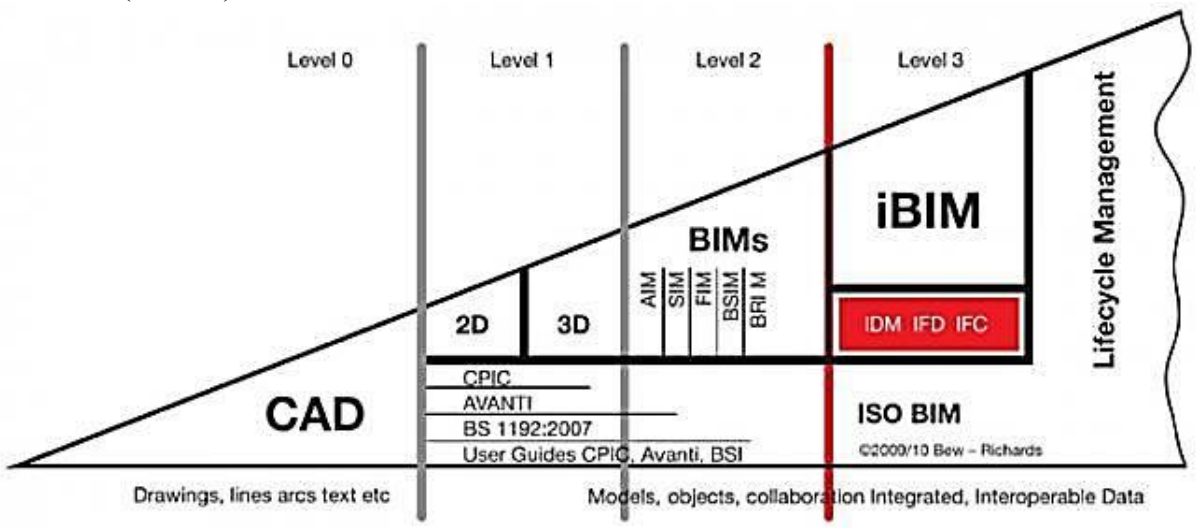

Fig. 2. Levels of the information model maturity.

The current state of BIM in the market is determined by the desire to reach the second level [3] according to the classification of maturity. This condition is determined by the presence of attributes that carry information not only about the elements themselves, but also systems of construction objects made up of model elements. Thus, the $3 \mathrm{D}$ model is filled with information about the physical parameters of structures, the affiliation of constructs to objects, and working documentation. An example of an intellectual attributefilled model of construction associated with work on the construction of a dry dock of shipyard is presented in figure 3. 


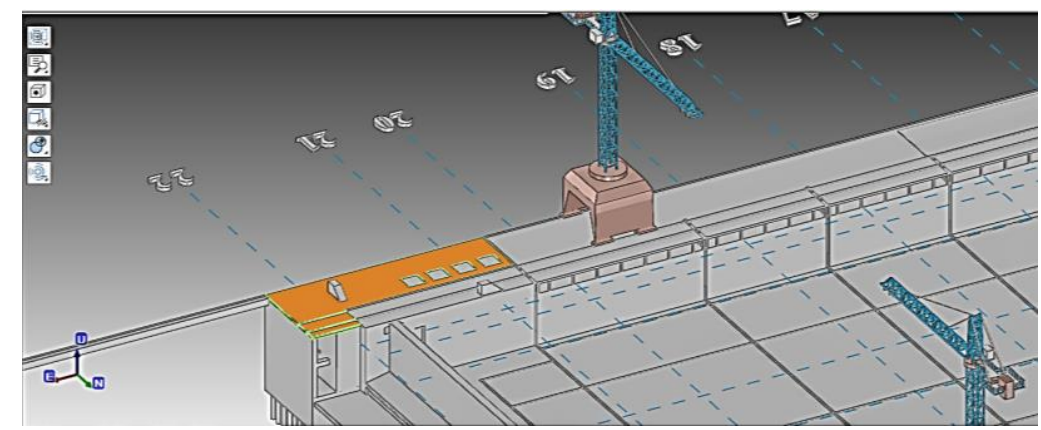

Fig. 3. Attributive filling of the dry dock model.

One of the criteria for determining the model to the second level is the linking of the time dimension to the existing three-dimensional construct. This phenomenon is called four-dimensional modeling (4D BIM) - the linking of 3D-models of objects with data from a scheduled network in order to improve construction planning techniques [4]. Nongeometric information can be added in a meaningful way, which can then be associated with the schedule data in the 4D model [5].

4D BIM has become a common abbreviation for linking various terms that appeared earlier, including 4D CAD, 4D modeling, 4D planning and compilation of scheduled network and 4D simulation [6]. This method was described in the early 1990s [7], and studies that have collected the result of using this technology have shown their potential to improve the transfer of graph data in construction projects [8].

The correct construction of 4D BIM requires three basic "input" requirements: a 3D geometric model; developed construction schedule, with the availability of information and works, logistic connections and time periods for the production of works; 4D modeling tool that allows you to link elements of a 3D model with elements of a graph [9]. In other words, the resulting model must be created taking into account: visualization of the temporal and spatial relationships of construction activities; analysis of the construction schedule to assess its implementation and the correct choice of construction technologies; reduce errors by checking the construction plan and improving communication between the project team. As a result, the terms of work are noticeably reduced and their effectiveness is increased.

One of the important components when working with the 4D BIM model is software, as the program's functionality and its applicability in geotechnical construction depend on the choice of the program. The most advanced software in this area is the product of Bentley Systems - SYNCHRO. This program not only has all the necessary functional list, but also a number of advantages [10] necessary for the successful application in the construction of large geotechnical objects. These include a combination of different platforms for design management, construction at all stages, and maintenance of the facility during the operational period. Due to this, at the design stage, you can see all the construction technologies and recognize spatio-temporal collisions that could be identified directly during the work, which, inevitably, would lead to the failure of target dates and increase the cost of the project. Also, Synchro has a wide range of solutions for the work production stage. In addition to the main Synchro PRO program for working with 4D BIM, there is a mobile application Synchro SITE, which allows you to make a huge part of the fact-making directly from the construction site, by changing the status of structures in the $4 \mathrm{D}$ object model and loading this data into the project database. The process of entering information from the site is instant for all project participants, regardless of their affiliation with the organization and their role in the project. Timely information received contributes to timely decision-making in the planning office. Figure 4 shows an example of information received 
from the site on the status of work on the installation of bored piles during the construction of dry dock structures of a shipyard.

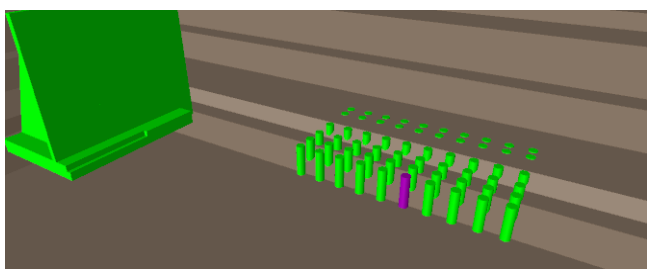

Fig. 4. Fact about the construction of bored piles under the western wall of the dry dock.

The introduction of new technologies and BIM-modeling is most justified in the construction of the industrial sector, as all parties are interested in the possibility of implementing the use of new technologies to reduce company costs, and have the financial resources to launch 'pilot' projects. Among the first projects, the construction of a dry dock for the Far Eastern shipbuilding complex was chosen.

Most of the dry dock structures are below the ground. The bottom is a massive concrete slab 1.5 meters thick on bored piles with a diameter of 1020 millimeters, buttresses, up to 14 meters deep. The size of the object in the plan is 485 by 114 meters. Based on the scale of construction of this complex in-depth structure, it was decided to test BIM management and planning technology.

At the stage of design and working documentation development, a 3D model was created that meets the level of detail for further work on managing construction on the site. Excessive detailing often turns out to be excessive for managing the object, since when working with 4D BIM it is important to determine and select a strategy for conducting construction and installation works. Also, at the current stage, a 4D construction model was launched with the planning of work not lower than the 3rd level of development. At this stage, the main goal was to identify spatial collisions in the developed schedule and its revision. The general strategy of the work is presented in a series of figures 5-8.

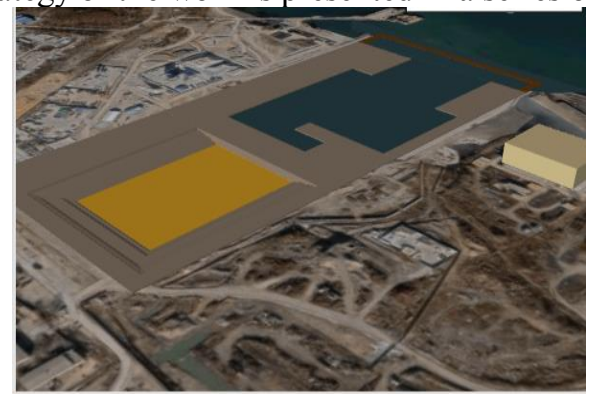

Fig. 5. Excavation of the pit.

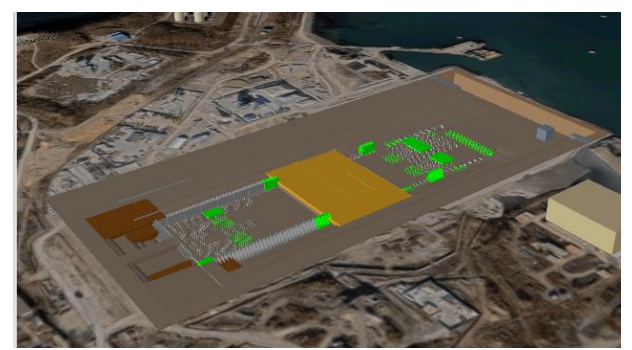

Fig. 6. Construction of pile field, dock walls, dock bottom slabs. 


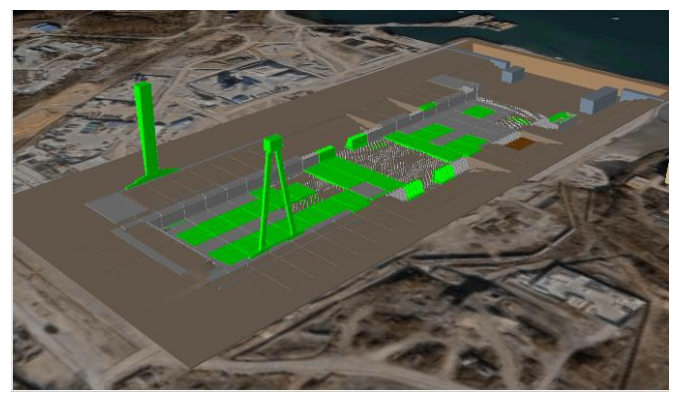

Fig. 7. Mounting the gantry crane.

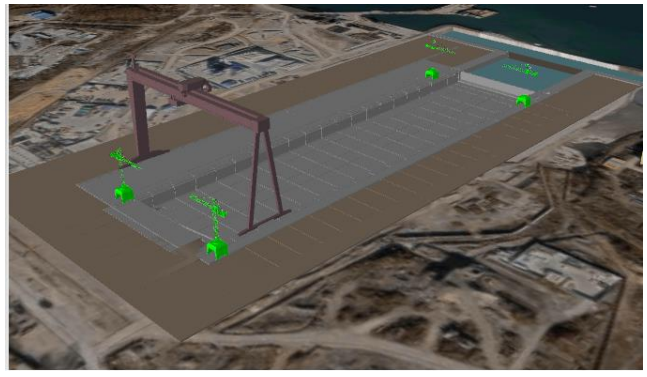

Fig. 8. Completion of construction and installation works.

The project is in the process of carrying out construction work. The main work with the model at the current stage is to collect actual data on the execution of work directly at the construction site, load this data into the model and recalculate the timetable of the schedule. Departments of the production construction management receive information on the progress of the work from the model, while contractors on the construction site receive relevant weekly-daily tasks. Already now we can talk about the positive impact of the use of 4D BIM. Actual deadlines correspond to planned dates. In the future, information will be collected on the progress of the project and conclusions will be drawn on the appropriateness and applicability of 4D BIM in the structure of the customer-company.

Another example of the application of 4D BIM was a project for the reconstruction of the buildings of the blast furnace shop of a metallurgical plant. The task was to optimize the timing of the construction and installation work operation of the stop period by using 4D modeling. The technology was tested on the buildings of the bunker overpass and the central supply station, shown in figures 9 and 10. During the simulation of possible scenarios for dismantling and installation works, the visibility of the 4D BIM model revealed spatio-temporal collisions in the installation of the lining of bunkers and in the installation of the supply units. The project team proposed technological solutions for the simultaneous installation of the lining of the bunkers, taking into account the cramped conditions of work near the bunkers. The order of construction of the supply units and their enlarged assembly was also changed. 


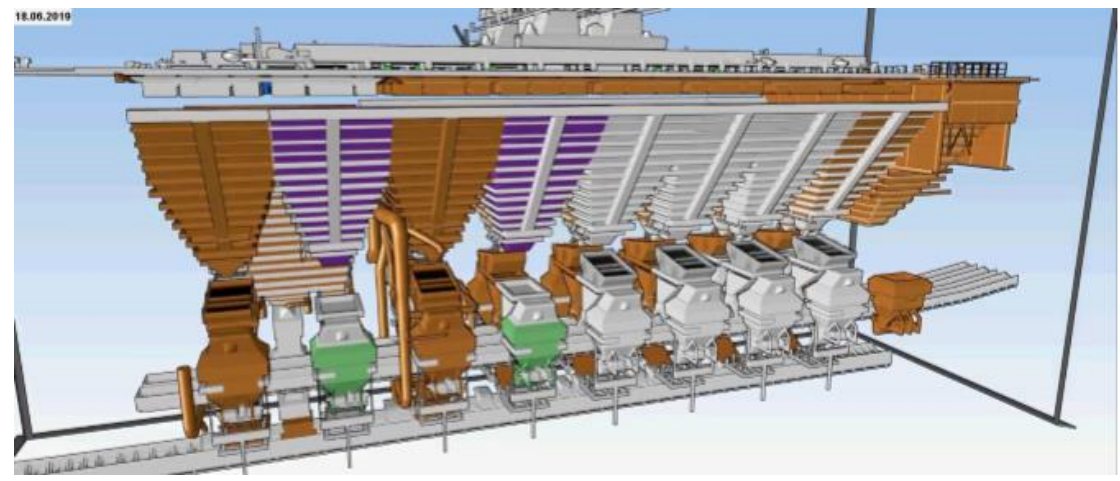

Fig. 9. Pairwise works for reconstruction of bunkers.

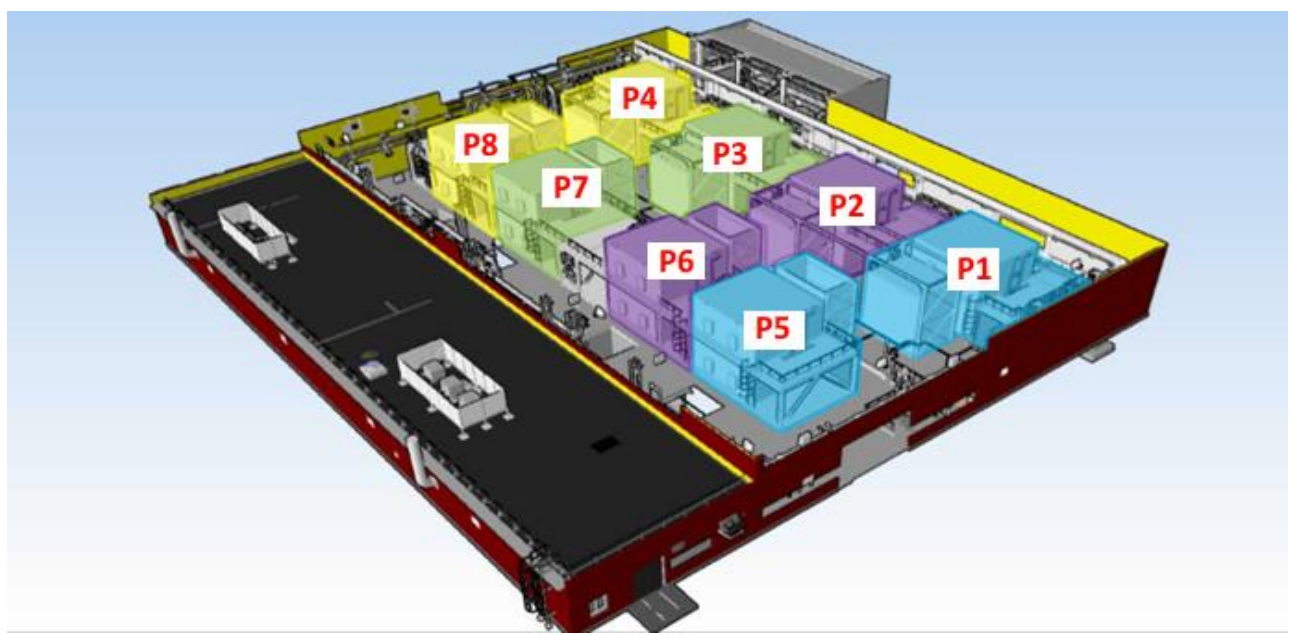

Fig. 10. Technological sequence of installation of the supply units P1-P8.

The measures taken allowed to reduce the duration of stopping work from 130 days to 122 days in the building of the bunker overpass and from 130 days to 116 days in the building of the central supply station.

At the end of the project, a calculation of the economic efficiency of the use of 4D BIM was made while reducing the time for construction and installation works. The calculation for the building of the bunker overpass and the central supply station was made in accordance with Building Standards 509-78. The calculation results are presented in table 1.

Table 1. The result of the calculation of economic efficiency.

\begin{tabular}{|c|c|c|}
\hline Reconstruction object & Bunker overpass & Central supply station \\
\hline $\begin{array}{c}\text { Estimated cost of construction and installation } \\
\text { works, thousand rubles }\end{array}$ & 1394193.801 & 1242273.455 \\
\hline $\begin{array}{c}\text { Estimated cost of construction and installation } \\
\text { work, including VAT in 2018, thousand rubles }\end{array}$ & 1645148.685 & 1465882.665 \\
\hline Conditionally fixed overhead costs, thousand rubles & 676793.107 & 603045.362 \\
\hline Savings on fixed costs, thousand rubles & 41648.807 & 64943.347 \\
\hline $\begin{array}{c}\text { Savings on fixed costs including VAT in 2018, } \\
\text { thousand rubles }\end{array}$ & 49145.592 & 76633.149 \\
\hline $\begin{array}{c}\text { Savings on conditionally fixed costs, \% of the cost } \\
\text { of construction and installation works }\end{array}$ & 2.99 & 5.23 \\
\hline
\end{tabular}


Thus, the economic efficiency from the use of 4D BIM in this project amounted to more than 105 million rubles.

As a second 'pilot' project, construction of a pier, one of the facilities of the marine shipping terminal of the industrial and logistics complex, was considered. This structure is a bulk territory of 30 thousand square meters, on which a retaining wall is being built - a pier, consisting of a sheet pile front wall made of pile pipes with a diameter of 1,420 millimeters, a Larsen sheet pile wall and anchor rods with a diameter of 100 millimeters. In this project, 4D BIM is used as an information project for the construction organization. After the development of the model, a decision was made to divide the geotechnical work into three fronts and to attract three contractors in order to fulfill the condition for the simultaneous completion of work on the front wall construction. Figures 11-18 provide a list of the main technological operations.

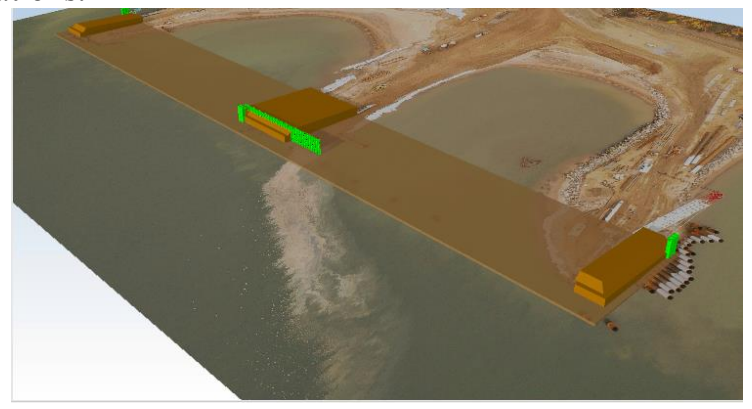

Fig. 11. Dumping the embankment to elevation $-2,500$, immersion piles of the front wall, immersion piles of the north and south wing walls.

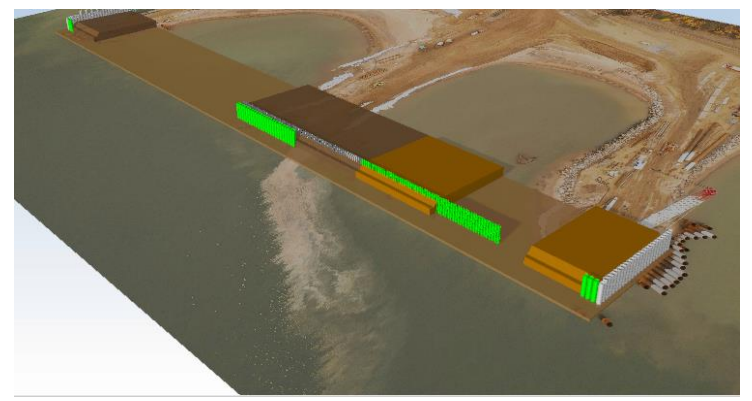

Fig. 12. Dumping the embankment to elevation $-2,500$, immersion of piles of the front wall, immersion of the temporary wall from the Larsen sheet pile.

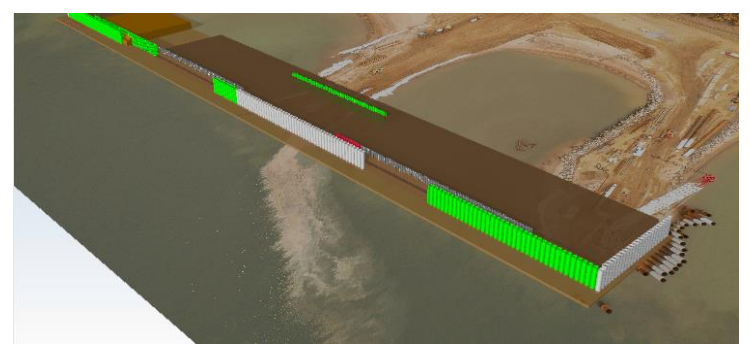

Fig. 13. Dumping the embankment to elevation $-2,500$, immersion of piles of the front wall, dismantling the temporary wall from the Larsen sheet pile, immersion of the Larsen sheet pile into the design position. 


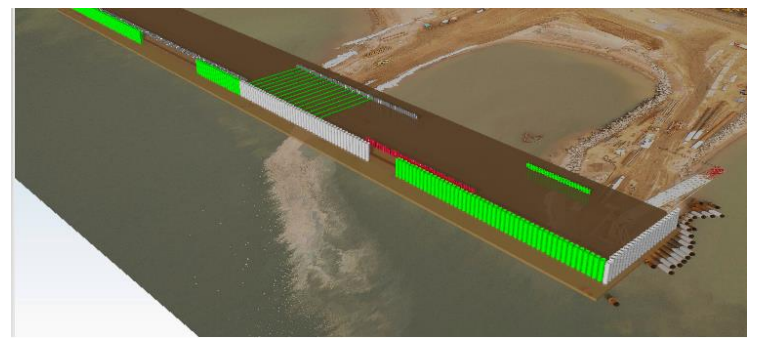

Fig. 14. Immersion of piles of the front wall, dismantling of the temporary wall from the Larsen sheet pile, immersion of the Larsen sheet pile in the design position, installation and tension of the anchor rods.

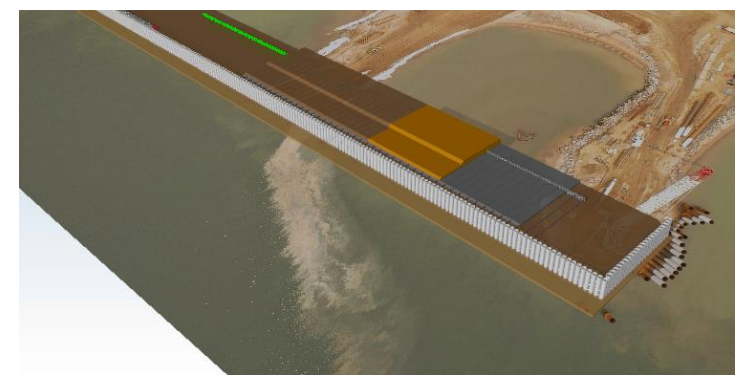

Fig. 15. Immersion of the Larsen sheet pile in the design position, installation and tension of anchor rods, filling with sand and gravel to the design level of $+0,000$.

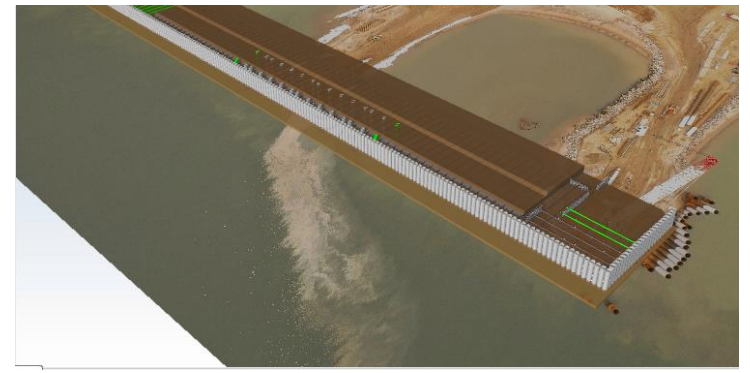

Fig. 16. Installation and tension of anchor rods, arrangement of Larsen sheet pile and anchor rods of the north and south wing walls.

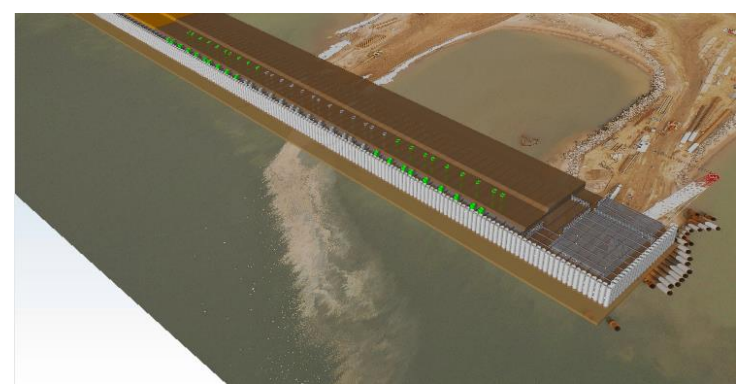

Fig. 17. Filling with sand and gravel to the design level of $+0,000$, immersion of piles of shells of the crane track. 


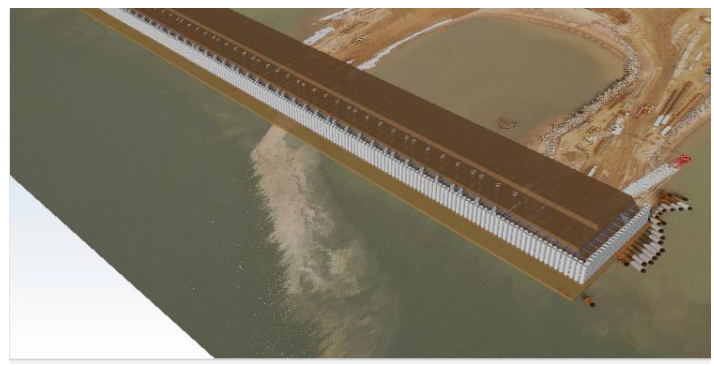

Fig. 18. Completion of work on the pier base.

Currently, work is underway to fill the territory and to arrange the front wall. With the help of the model, weekly-daily tasks are issued, reports are made on the progress of the work fulfillment, data are collected on the work performed. Work is being carried out in accordance with planned dates. After the end of this project, a decision will be made on the implementation of 4D BIM in all construction projects of the company.

\section{Conclusion}

The practice of applying the new management method in the production of zero-cycle work allows us to solve the problematic situations associated with the organization of construction that arise during planning and construction. The most significant advantages of 4D modeling are visualization of construction work and visual communication between project teams, which leads to increased planning efficiency. In addition, 4D modeling helps in the development of detailed and accurate work plans, site planning, and on-site logistics management. Using visualization and communication, planners, contractors and the customer can achieve a better understanding of the scope and objectives of the project, which can significantly improve the planning processes and execution of zero-cycle work. The introduction of 4D modeling allows planners to identify spatio-temporal collisions before the construction phase, which leads to a decrease in the amount of additional work and compliance with the project deadlines.

Digitalization of geotechnical works has great potential for significantly reducing the time and cost of construction. 4D BIM technology has just begun to penetrate the Russian market, while this technology is actively used in foreign practice. In the coming years, more information will be received on the results of the introduction of this technology in all areas of construction. Based on existing data, it can be argued that the application of this technology is cost-effective.

\section{References}

1. J. Crowther, S.O. Ajayi, International Journal of Construction Management, 1-14 (2019)

2. W. Smits, M.V. Buiten, T. Hartmann, Building Research \& Information 45(3), 336346 (2017)

3. I.Yu. Lavrov, M.O. Korovkin, N.A. Eroshkina, S.M. Sadenko, L.A. Kabanova, Theory. Practice. Innovation, (2019)

4. B.J. Gleeson, D.J. Greenwood, ITcon 21, 57-71 (2016)

5. S. Zhanga, J. Teizera, J.K. Lee, C.M. Eastman, M. Venugopala, Automation in Construction 29, 183-195 (2013) 
6. R. Büchmann-Slorup, N. Andersson, In Proc., 27th Int. Conf. of the CIB W78, 113-123 (2010)

7. A. Retik, A. Warszawski, A. Banai, Building and Environment 25(2), 133-142 (1990)

8. A.G. Hoseini, J.E. Tookey, O. Efimova, Renewable and Sustainable Energy Reviews, Elsevier 75, 1046-1053 (2017)

9. N. Dawood, S. Sikka, Engineering, Construction and Architectural Management, (2009)

10. A.L.C. Ciribini, S.M. Ventura, M. Paneroni, Automation in Construction 71, 62-73 (2016) 